\title{
Heat and dry islands observed over Jakarta, Indonesia, in 2012
}

\author{
HASTI WIDYASAMRATRI, KAZUYOSHI SOUMA, TADASHI SUETSUGI, \\ HIROSHI ISHIDAIRA, YUTAKA ICHIKAWA, HIROSHI KOBAYASHI, \\ ICHIKO INAGAKI \& KAZUHIRO KAKIZAWA
}

University of Yamanashi, 4-3-11 Takeda, Kofu, Yamanashi 400-8511, Japan

g11dea03@yamanashi.ac.jp

\begin{abstract}
Recent population increases in urban areas of Asian countries have extended artificial land cover, increased energy consumption, and caused various problems. Higher air temperatures over urban areas (heat islands) degrade residential environments and affect human health. In Jakarta, the largest city in Indonesia and the second largest city in Asia, previous studies have relied on only a few observation points and physically-based models. To study the thermal environment in Jakarta in more detail, we performed seven fixed-point temperature and humidity observations from the dry to the pre-monsoon season (from 16 September to 18 October) in 2012. Over densely urbanized areas, higher temperatures and lower humidity were observed around noon compared with the sparsely urbanized areas. The maximum differences in temperature and specific humidity were found to be around $3^{\circ} \mathrm{C}$ and $0.005 \mathrm{~kg} / \mathrm{kg}$, respectively. The differences in temperature and humidity became smaller in the afternoon because of the penetration of sea breezes. At night, the differences became larger again because the sea breeze weakened. Then, a difference of around $3{ }^{\circ} \mathrm{C}$ was observed, except in the early morning. Although the difference in daytime temperature was smaller between densely urbanized areas and suburban areas, similar tendency was also confirmed in the daily time series averaged for sunny days in dry season.
\end{abstract}

Key words urbanization; heat island; dry island; Jakarta; observational analysis

\section{INTRODUCTION}

Recently, Asian countries have experienced rapid urbanization. In Indonesia, the ratio of the population in urban $v s$ rural areas in 2000 was 3.59 times higher than that in 1980 (United Nations 2011). This increase was considerably greater than that in the rest of Asia (2.58) and the world (2.03) (United Nations 2011). Population concentration in urban areas extends artificial land cover, increases energy consumption, and causes various problems. Higher air temperatures over urban areas (heat islands; e.g. Oke 1967, Hung et al. 2006, Kataoka et al. 2009) degrade residential environments and increases the risk of heat-related illnesses (e.g. Tan et al. 2010). Thus, monitoring temperatures and investigating heat islands over Asian megacities are pressing concerns.

In Jakarta, the largest city in Indonesia and the second largest city in Asia, urban areas have also expanded rapidly over the past few decades. Present-day Jakarta and the extended zone surrounding it (Jakarta, Bogor, Tangerang and Bekasi) cover a total of $7500 \mathrm{~km}^{2}$ (Goldblum and Wong 2000). Studies examining the intensity and extension of heat islands (e.g. Tokairin et al., 2010) have relied on only a few observation points (only two airport observations) and on physically-based models. To understand the thermal environment in Jakarta in detail, denser observations are needed.

In this study, we therefore performed fixed-point observations in Jakarta from the dry to premonsoon season.

\section{OBSERVATION EQUIPMENT, PERIOD AND SITES}

For the fixed-point observation, we used the HOBO Pro v2 U23-002 as a thermo-hygrometer, the Mistral Instruments WDL-01 as an aerovane, and the Optex MI-710 as an infrared thermometer. The thermo-hygrometers were set $1.5 \mathrm{~m}$ above the ground in forced-draft shelters with solar batteries (Field Pro 380-283), and the aerovanes were set at $2.0 \mathrm{~m}$ height.

The fixed-point observation was performed from 16 September to 18 October 2012. Seven thermo-hygrometers, two aerovanes, and one infrared land-surface thermometer data were used for the analysis (Fig. 2). Site 1 (Cibinong) represents an inland suburban area, Site 2 (Kramat Jati, Jakarta) represents a densely urbanized area, Site 3 (Tangerang) represents a densely urbanized area close to the sea, and Site 4 (Tambun) represents a suburban area close to the sea. 


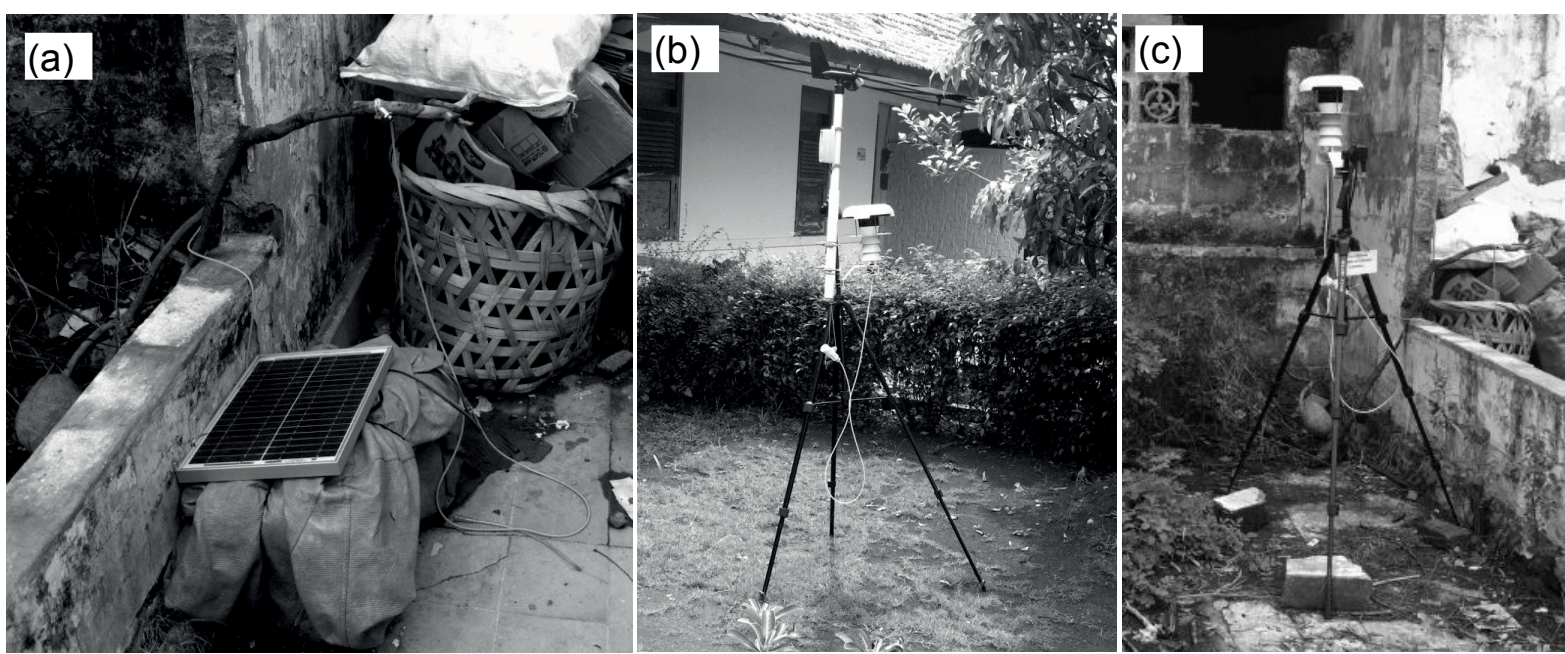

Fig. 1 Fixed-point observation equipment: (a) the infrared land surface thermometer, (b) the aerovane, and (c) the thermo-hygrometer.

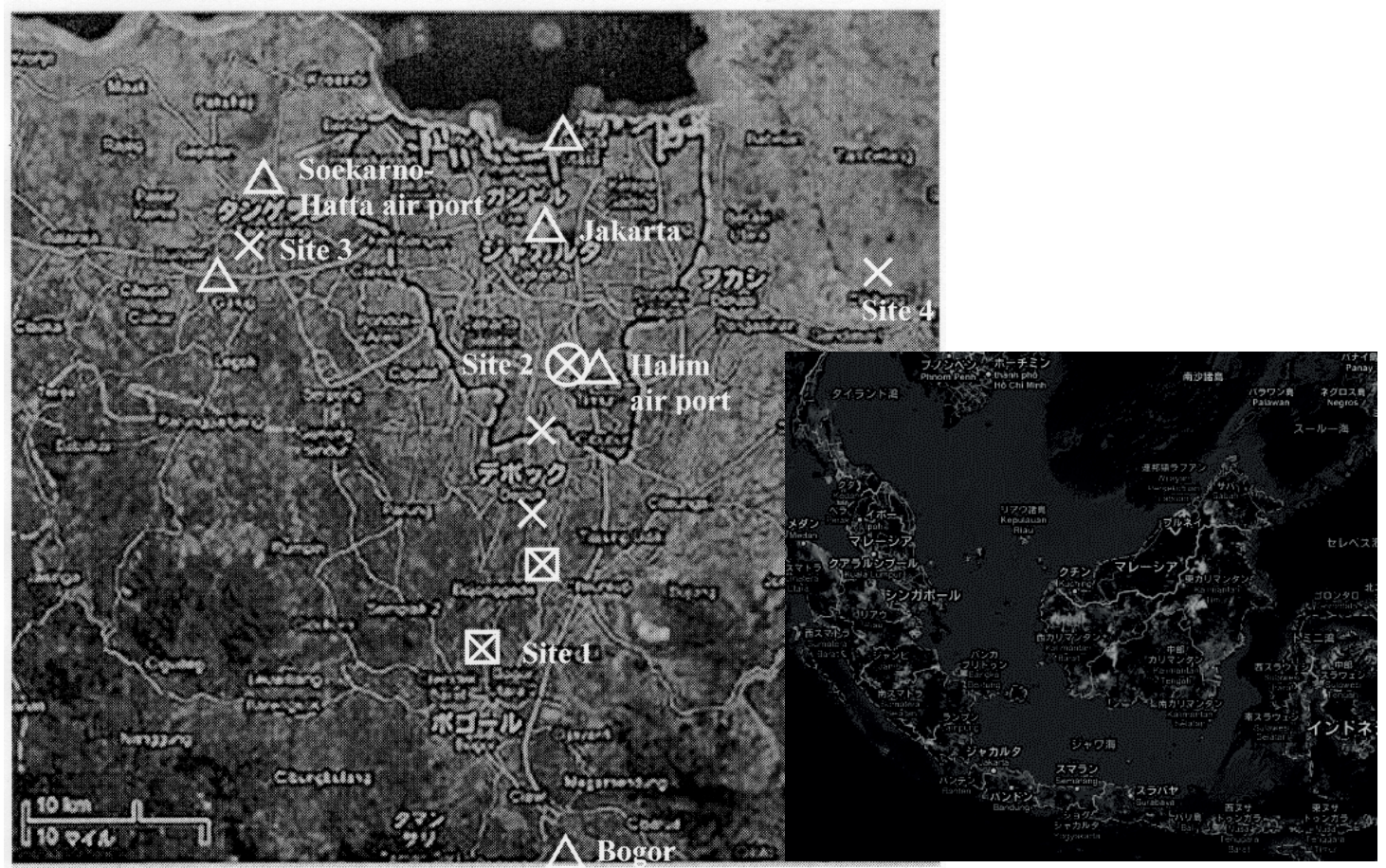

Fig. 2 Sites for the fixed-point observation. Cross marks indicate thermo-hygrometers, squares indicate aerovanes, and the circle indicates a thermometer. The triangles indicate observatories in NOAA's National Climatic Data Center (NCDC). Google Maps (http://maps.google.co.jp/maps) was used to create this figure.

\section{RESULTS AND DISCUSSION}

Figure 3 shows the 6-hourly rainfall amount during the observation period (16 September to 18 October) at Jakarta and Bogor. At Bogor, which is close to the southern mountainous area, frequent rainfalls were seen, especially in October. We chose 16 September 2012, a day on which no rainfall was observed at the five observatories, as representative of a dry season, sunny day.

Figure 4 shows the air temperature and specific humidity observed on 16 September 2012. Before 12:00 LST, the air temperature was higher over densely urbanized areas (Sites 2 and 3) than at other sites because of strong heating caused by artificial land cover and anthropogenic heat. The maximum difference was around $3{ }^{\circ} \mathrm{C}$ at around 12:00 LST. 
After 12:00 LST, the increase in air temperature was suppressed over Sites 2 and 3 because the sea breezes penetrated and carried cold air from the Java Sea. In contrast, the air temperature increased over the inland suburban area (Site 1) because the sea breezes carried heated air from densely urbanized areas inland. During the daytime, the air temperature was lower over suburban areas close to the sea (Site 4) compared with other sites. During the night-time, air temperatures over densely urbanized areas (Sites 2 and 3) were clearly higher than those over suburban areas (Sites 1 and 4), because the urban geometry prevented radiation cooling. The difference in temperature was around $3^{\circ} \mathrm{C}$ during the night-time, except in the early morning.

Figure 5 shows the wind direction on 16 September at the Halim Airport observatory, close to Site 2. From the wind direction, the penetration of sea breezes (change in wind direction from eastward to northward) was observed at 13:00 LST. This timing was consistent with the time at which the suppression of temperature rise was observed at Site 2 .

The specific humidity was lower over the densely urbanized area (Sites 2 and 3) in the midmorning because evapotranspiration from vegetation was lower than that over the suburban area. A dry island developed over the centre of Jakarta, where lower humidity was observed over the densely urbanized area compared with the suburban area (e.g., Deosthali, 2000; Watanabe, 2012). The maximum difference in specific humidity was $0.005 \mathrm{~kg} / \mathrm{kg}$. Around noon, the specific humidity also decreased in the inland suburban area (Site 1) because of the effects of the densely urbanized area close to the sea. In the afternoon, specific humidity increased from the coastal area to the inland area because sea breezes carried water vapour from the Java Sea inland. At night, sea breezes became weak, but specific humidity remained high over the coastal sites (Site 3 and 4). Over the inland area (Site 1), mountain breezes from the south seemed to supply water vapour.
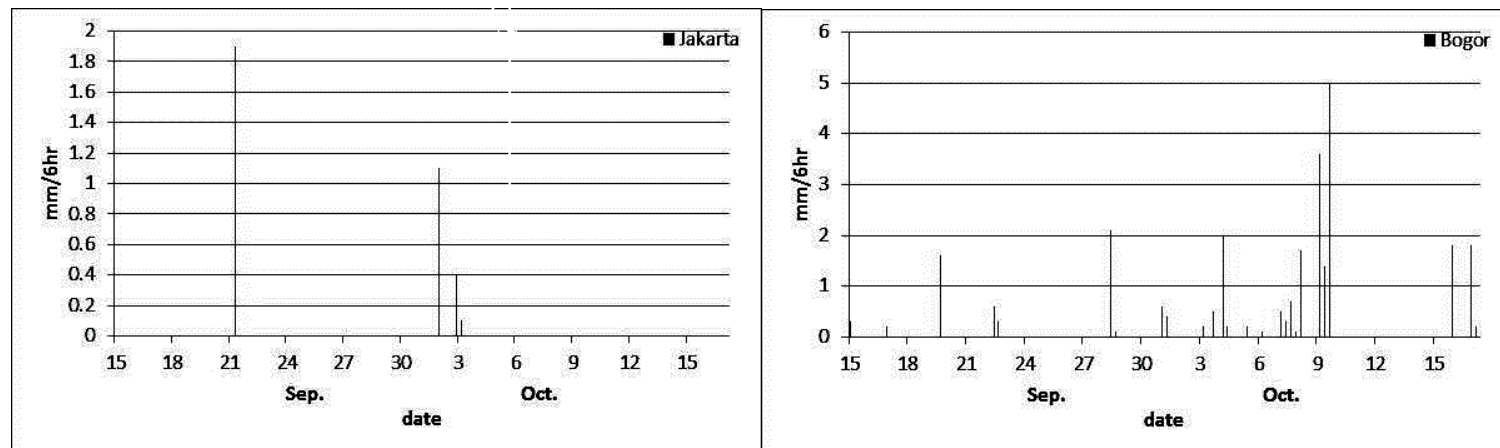

Fig. 3 Six-hourly rainfall during the observation period (from 16 September to 18 October) at the observatories (left; Jakarta, right; Bogor).


Fig. 4 Observed temperature (left) and specific humidity (right) on 16 September. 


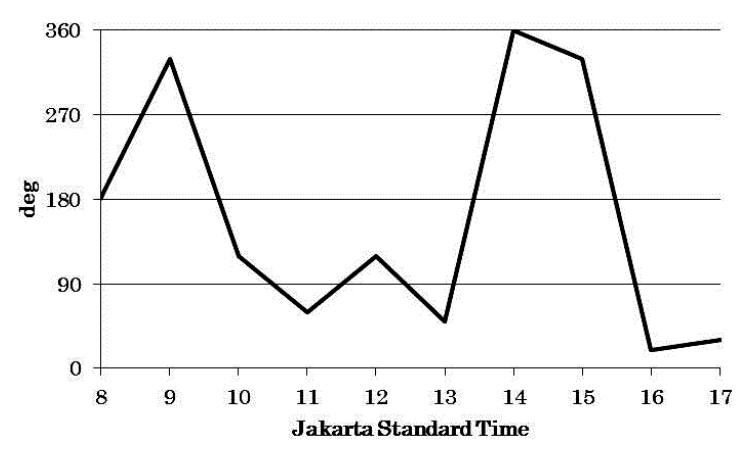

Fig. 5 Wind direction on 16 September at the Halim Airport observatory. Here, $0^{\circ}\left(360^{\circ}\right)$ indicates northward wind, and $180^{\circ}$ indicates southward wind.
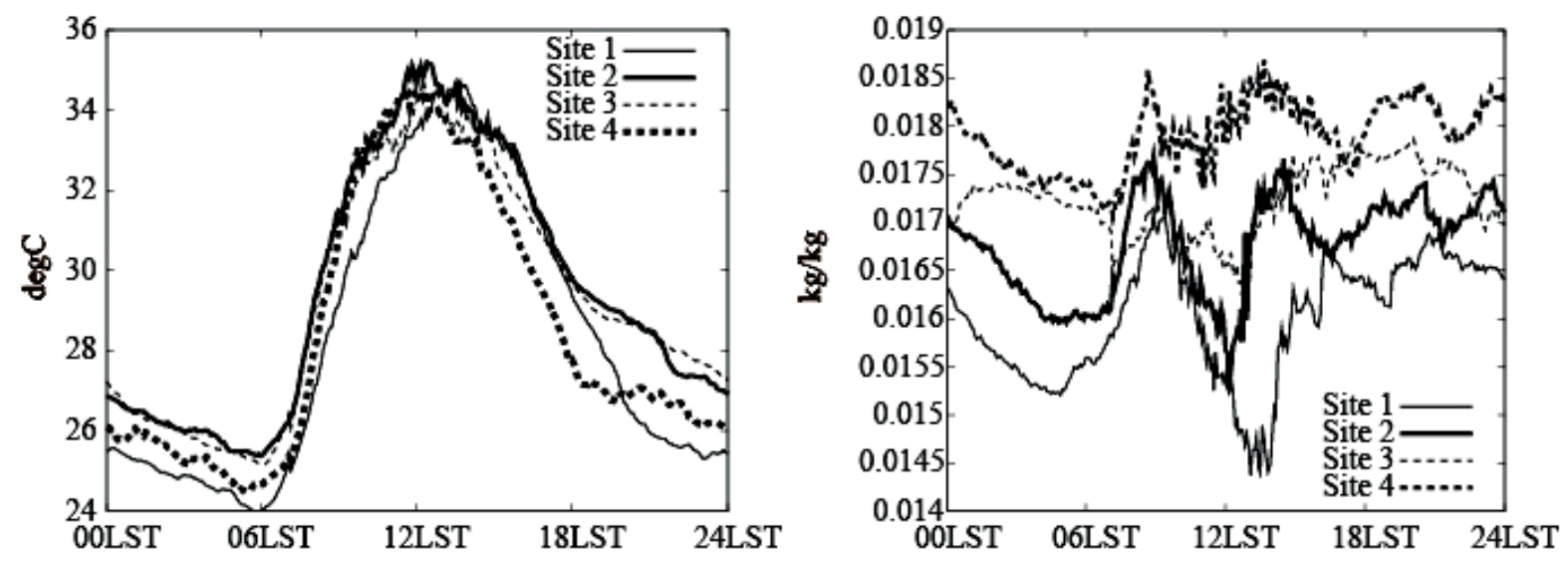

Fig. 6 Observed temperature (left) and specific humidity (right) averaged on dry season sunny days (16, $19,22,26,27,28$ September).

Figure 6 shows the daily time series averaged for sunny days in dry season $(16,19,22,26,27$, 28 September). The dry season sunny days were defined as the days when no rainfall was observed in observatories in NCDC within the target area (shown in Fig 2) in September. Higher temperature over densely urbanized areas (Site 2) was also confirmed, however, the difference between densely urbanized areas and urban areas (Site 1, Site 4) was not large compared with 16 September (around $1^{\circ} \mathrm{C}$ ). The suppression in air temperature rising over Site 2 and 3 after $12 \mathrm{LST}$, and delay in suppression over the inland suburban area (Site 1) because the sea breezes carried heated air from densely urbanized areas inland. During the night-time, air temperatures over densely urbanized areas (Sites 2 and 3) were also clearly higher than those over suburban areas (Sites 1 and 4), and the difference in temperature was around $3^{\circ} \mathrm{C}$ during the night-time, except in the early morning.

The specific humidity was also lower over the densely urbanized area (Sites 2 and 3) and inland suburban area in the mid-morning to afternoon. In the afternoon, humidity also increased from the coastal area to the inland area by the sea breezes from the Java Sea. At night, sea breezes became weak, but specific humidity remained high over the coastal sites (Sites 3 and 4).

\section{SUMMARY}

In this study, to understand the thermal environment in Jakarta in detail, seven fixed-point temperature and humidity observations were performed in Jakarta from the dry to pre-monsoon season (16 September to 18 October) in 2012. Over densely urbanized areas, higher temperature and lower humidity were observed compared with over the sparsely urbanized areas around noon. The maximum differences in temperature and specific humidity were around $3^{\circ} \mathrm{C}$ and $0.005 \mathrm{~kg} / \mathrm{kg}$, respectively. The differences in temperature and humidity became smaller in the afternoon due to the penetration of sea breezes. At night, the differences became larger again because of the 
weakened sea breezes. At night, a difference of around $3^{\circ} \mathrm{C}$ was observed, except in the early morning. Although the difference in daytime temperature was smaller between densely urbanized areas and suburban areas, similar tendency was also confirmed in the daily time series averaged for sunny days in dry season.

These results reveal clear heat and dry islands over Jakarta. These observation data can be used to validate physically based meteorological models and satellite remote sensing, and finally to aid sustainable urban development in Jakarta.

Acknowledgements The authors thank Prof. Kengo Sunada and Dr Jun Magome at the University of Yamanashi, Dr Ratih Indri Hapsari at the State Polytechnic of Malang, Indonesia, Prof. Satoru Oishi at Kobe University, and Dr Kenji Tanaka and Prof. Eiichi Nakakita at Kyoto University for helpful comments. This study was supported by the special coordination funds (SCF) for promoting science and technology of the Global Center of Excellence (GCOE) program of the University of Yamanashi, by Grants 22246066, 22226010, 13305033, 16360244, 24760390, and as part of the program for Improvement of the Research Environment for Young Researchers, SCF, from the Ministry of Education, Culture, Sports, Science and Technology, Japan.

\section{REFERENCES}

Deosthali, V. (2000) Impact of rapid urban growth on heat and moisture islands in Pune City, India. Atmospheric Environment $34,2745-2754$.

Goldblum, C. and Wong, T.-C. (2000) Growth, crisis and spatial change: a study of haphazard urbanization in Jakarta, Indonesia. Land Use Policy 17, 29-37.

Hung, T., et al. (2006) Assessment with satellite data of the urban heat island effects in Asian mega cities, International Journal of Applied Earth Observation and Geoinformation 8, 34-48.

Kataoka, K., et al. (2009) Urban warming trends in several large Asian cities over the last 100 years. Science of the Total Environment 407, 3112-3119.

Oke, T. R. (1967) City size and the urban heat island. Atmospheric Environment 7, 769-779.

Tan J., et al. (2010) The urban heat island and its impact on heat waves and human health in Shanghai. International Journal of Biometeorology 54, 75-84.

Tokairin, T., Sofyan, A. and Kitada, T. (2010) Effect of land use changes on local meteorological conditions in Jakarta, Indonesia: toward the evaluation of the thermal environment of megacities in Asia. International of Climatology 30, 1931-1941.

United Nations, Department of Economic and Social Affairs, Population Division (2011) World Urbanization Prospects: The 2011 Revision.

Watanabe, K., Fujii, K. and Moriwaki, R. (2012) Urban dry island phenomenon in Matsuyama Plain. Journal of Japan Society of Civil Engineers, Ser. B1 (Hydraulic Engineering) 67(4), pp.I_1765-I_1770 (in Japanese with English abstract). 